\title{
Preparation and Characterization of PVA/Zinc Acetatel Boron Composite Fibers
}

\author{
Ibrahim Uslu, ${ }^{1^{*}}$ Burcu Başer, ${ }^{2}$ Ahmet Yaylı, ${ }^{3}$ Mehmet Levent Aksu ${ }^{4}$ \\ ${ }^{1 *}$ Selcuk University, Education Faculty, Meram Yeniyol, Meram, Konya, Turkey; fax: \\ +90 332323 8225; e-mail: uslui_1955@yahoo.com \\ ${ }^{2}$ Gazi University, Faculty of Science, Beşevler, Ankara, Turkey \\ ${ }^{3}$ Turkısh Atomic Energy Authority, Cekmece Nuclear Research Center \\ ${ }^{4}$ Gazi University Education Faculty, Beşevler, Ankara, Turkey
}

(Received: 28 August, 2007; published: 28 November, 2007)

\begin{abstract}
The objective of this work was to synthesize boron incorporated PVA/Zinc acetate nano precursor composite polymer fibers using electrospinning technique. Produced fibers, are useful reagents in organic synthesis of zinc oxide nano structures which have gained wide interest because of their potential applications in the fabrication of microelectronic devices. Boron incorporated PVA/Zinc acetate not only improve the electrical properties of $\mathrm{ZnO}$ films but also has an influence on the crystal structure of $\mathrm{ZnO}$ films. The fibers were measured and characterized by conductiometer (with four-point probe), Fourier transform infrared spectroscopy (FT-IR), scanning electron microscopy (SEM), differential scanning calorimetry (DSC) and thermogravimetric analysis (TGA). The formation of boron incorporated PVA/Zinc acetate hybrid polymer was confirmed by FT-IR spectra. SEM micrographs clearly reveal that there are random-growth oriented fibers on aluminum foil with diameters ranging from 0.5 to $1 \mu \mathrm{m}$. According to the TGA analysis decomposition of zinc acetate from the PVA chain was observed around $273{ }^{\circ} \mathrm{C}, 368{ }^{\circ} \mathrm{C}$ and $447^{\circ} \mathrm{C}$. Boron incorporated PVA/Zinc acetate nano composite polymer fibers have been successfully synthesized for the first time using electrospinning technique and characterized in detail as precursor material for $\mathrm{ZnO}$. Electrospinning process has been a widely used, simple and versatile method and in future may be used for large-scale preparation of nanofibers of $\mathrm{ZnO}$.
\end{abstract}

\section{Introduction}

The synthesis of one dimensional (1D) metal oxide nano structures, such as nanorodes, nanowires, have gained wide spread interest in recent years because of their potential applications in the fabrication of micro electronic devices [1-4]. Metal acetates such as zinc acetate, are useful reagents in organic synthesis of metal oxide nano structures. Several groups have reported $\mathrm{ZnO}$ nanofibers prepared by different techniques such as sol-gel [5], chemical vapor deposition (CVD) [6], alloy evaporation deposition method [7], self-catalyzed vapor-liquid-solid growth [8] and electrospinning process $[3,5]$. According to the literature, the electrical properties of $\mathrm{ZnO}$ films were improved by boron doping. Boron doping has also an influence on the crystal structure of $\mathrm{ZnO}$ films [9-11]. For instance the optical band gap energy is $3.22 \mathrm{eV}$ for undoped $\mathrm{ZnO}$ films and 3.32 for boron doped films [11]. There has been little work on the synthesis of boron-incorporated $\mathrm{ZnO}$ film using PVA/zinc acetate semi-inorganic polymer. Boron can form covalent molecular network like carbon atoms and can be incorporated into the backbone of a polymer chain like PVA through B-O bonds to produce semi-inorganic polymers [12-14]. The objective of this 
work was to synthesize boron incorporated PVA/Zinc acetate nano precursor composite polymer fibers using electrospinning technique. In this study, electrospinning technology is selected because of its simplicity. Electrospinning system consists of a high voltage power supply, syringe pump and a collector.

\section{Results and discussion}

\section{Fiber Conductivity}

The conductivity of the polymer fibers measured using four point probe technique (ENTEK company) after the samples were vacuum dried over night at $70{ }^{\circ} \mathrm{C}$ are presented in Table 1. When the amount of $\mathrm{Zn}$ acetate in PVA solutions was increased the conductivity of the polymer was observed to decrease as given in Table 1.

Tab. 1. Conductivity of the samples.

\begin{tabular}{lcccc}
\hline & \multicolumn{3}{c}{ Fiber conductivity } \\
\cline { 2 - 5 } & Solution I & Solution 2 & Solution 3 & Solution 4 \\
\hline Zn Acetate / PVA ratio & 1 & 2 & 3 & $0.23 \mathrm{~g} \mathrm{BA}$ added to \\
& & & & Solution 2 \\
\hline Conductivity $\left(\mathrm{S} \mathrm{cm}^{-1}\right)$ & $1.8 \times 10^{-5}$ & $1.2 \times 10^{-5}$ & $7.8 \times 10^{-6}$ & $4.0 \times 10^{-6}$ \\
\hline
\end{tabular}

Fiber Morphology

The morphology of the fibers was examined using a Quanta 200 FEG E-SEM scanning electron microscopy and presented in Fig. 1.
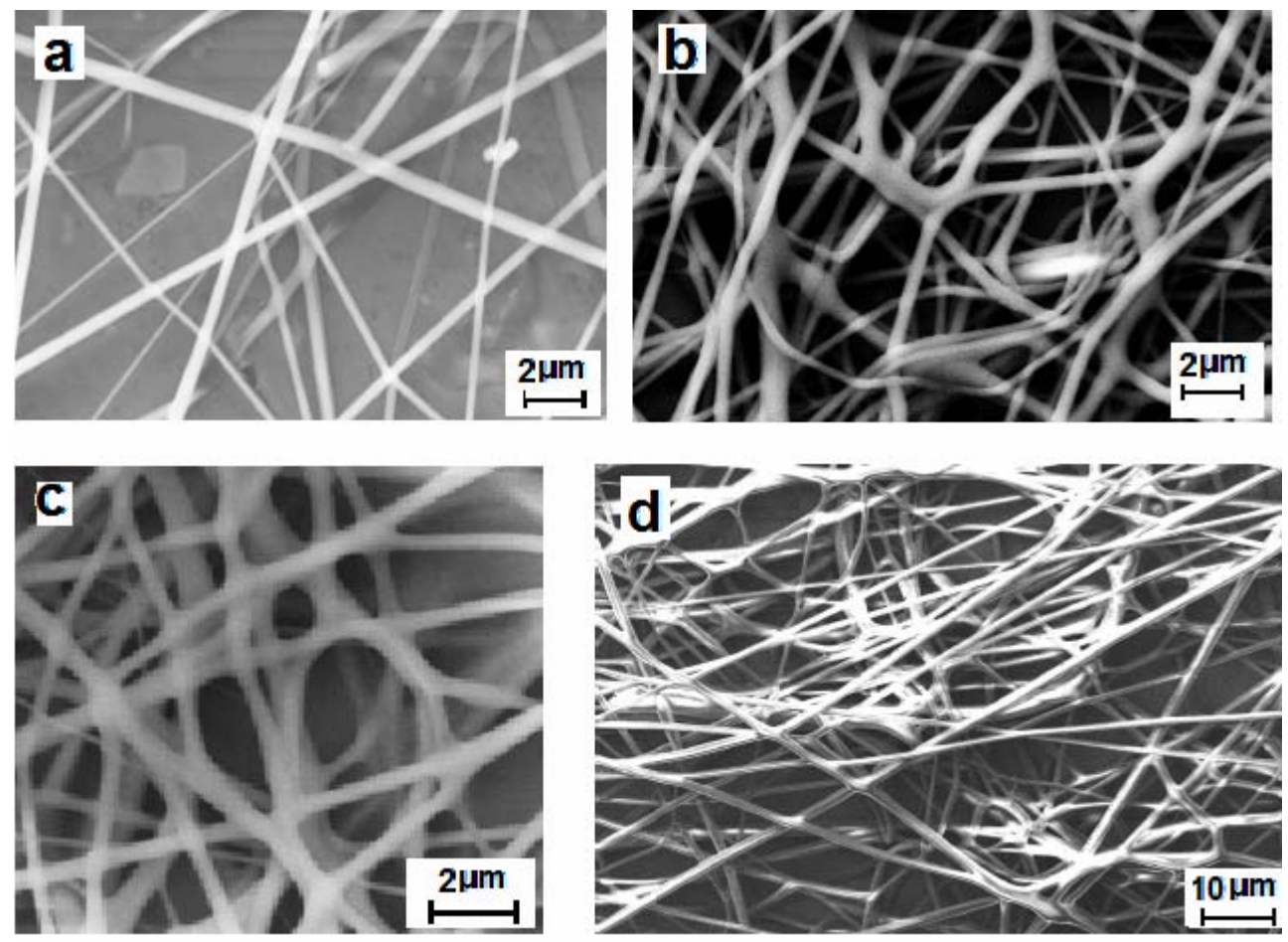

Fig. 1. Selected SEM images of samples a) Sample 1 (Zinc acetate to PVA ratio of 1), b) Sample 2 (Zinc acetate to PVA ratio of 2) c) Sample 3 (Zinc acetate to PVA ratio of 3) d) Sample 4 (Zinc acetate to PVA ratio 2 doped with $0.23 \mathrm{~g}$ boric acid). 
SEM micrographs clearly reveal that there are random-growth oriented fibers on aluminum foil with diameters ranging from 0.5 to $1 \mu \mathrm{m}$. The fiber diameters are not homogeneous and uniformly distributed. When the amount of $\mathrm{Zn}$ acetate is increased, average spacing between the fibers are observed to decrease. Also the cross linking of the polymers and their fiber density are dependent upon the amount of zinc acetate. In PVA/Zn/B4 sample, the highest cross linking was achieved by adding the boric acid (BA) to the solution.

\section{Thermogravimetric Analysis}

Figs. 2 and 3 show the thermal behavior of the precursor fibers of PVA/zinc acetate composites.

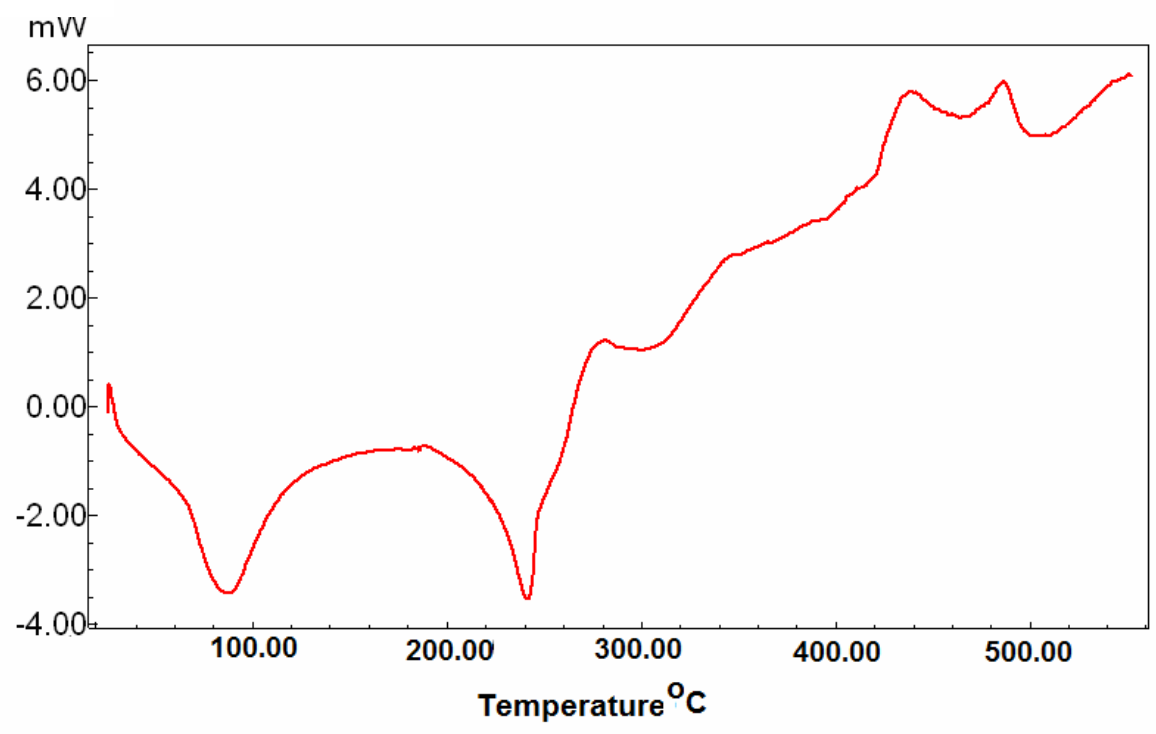

Fig. 2. DSC graph of the Sample 5 (Zinc acetate to PVA ratio 2 doped with $0.70 \mathrm{~g}$ boric acid).

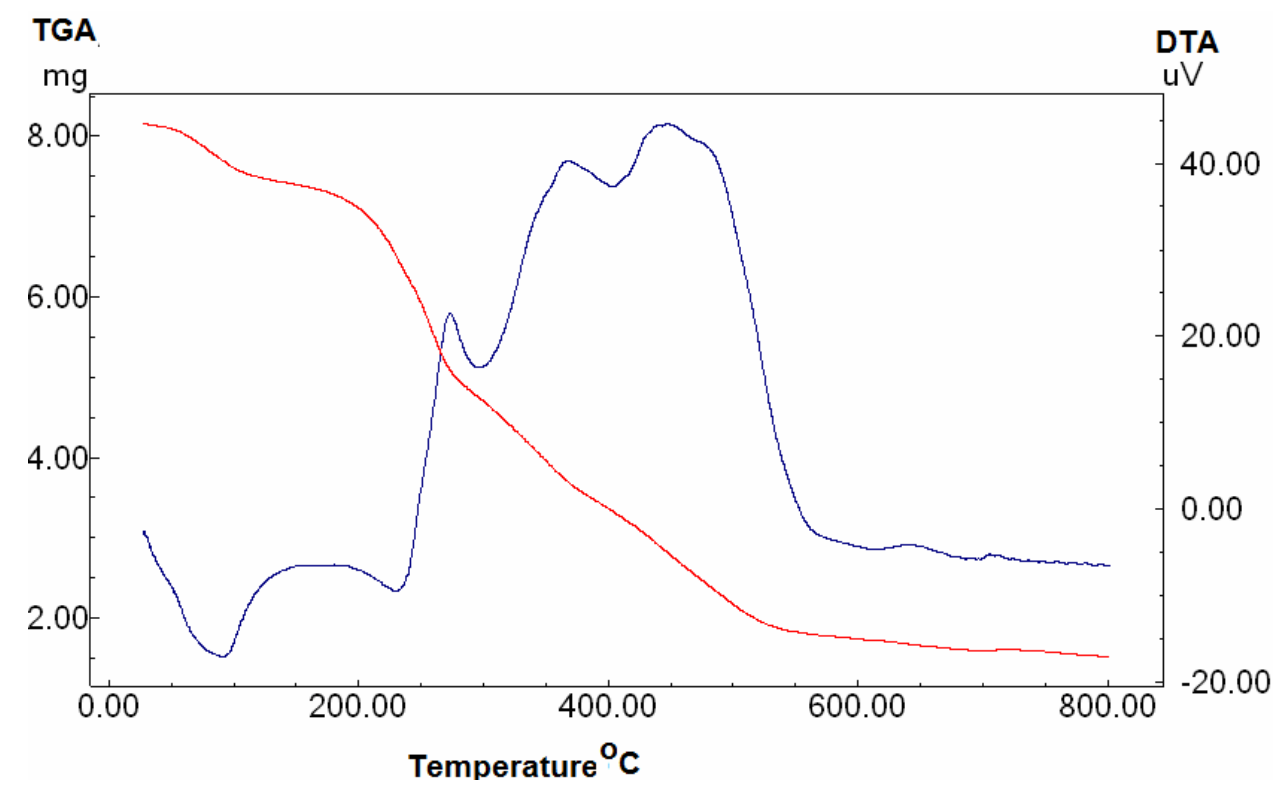

Fig. 3. TGA graph of the Sample 5. 
According to these figures most of the organic part of PVA and $\mathrm{CH}_{3} \mathrm{COO}$ group of zinc acetate and other volatile parts $\left(\mathrm{H}_{2} \mathrm{O}, \mathrm{COx}\right.$, etc.) were removed at temperatures $<500{ }^{\circ} \mathrm{C}$. According to the TGA analysis (Fig. 3), two endothermic peaks around 85 and $230{ }^{\circ} \mathrm{C}$ corresponds to the loss of absorbed water and the pyrolysis of PVA by dehydration on the polymer side chain [15-16]. Exothermic peaks observed around 273,368 and $447^{\circ} \mathrm{C}$ in the TGA curve can be attributed to the decomposition of zinc acetate and the main chain of PVA [15-17].

\section{FT-IR Analysis}

FTIR analyses of the samples are given in Fig. 4. All spectra have characteristic absorption peaks of $\mathrm{O}-\mathrm{H}$ stretching at $3400-3100 \mathrm{~cm}^{-1}, \mathrm{C}-\mathrm{H}$ stretching at $2900-2800$ $\mathrm{cm}^{-1}$. The absorption peaks at $1100-1000 \mathrm{~cm}^{-1}$ can be assigned as $\mathrm{C}-\mathrm{O}-\mathrm{C}$ stretching.

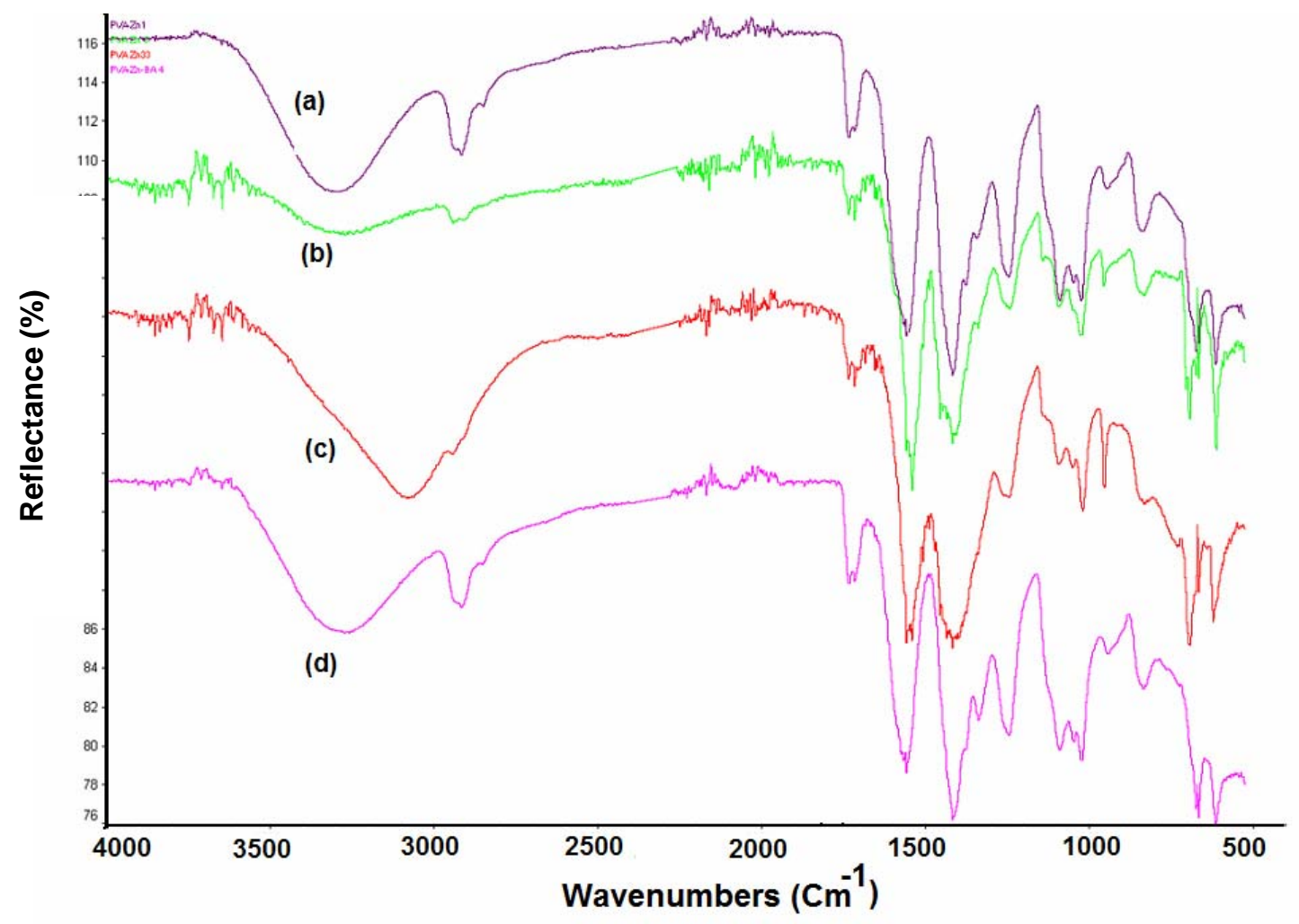

Fig. 4. FTIR Analysis of the a) Sample 1 (Zinc acetate to PVA ratio of 1), b) Sample 2 (Zinc acetate to PVA ratio of 2) c) Sample 3 (Zinc acetate to PVA ratio of 3) d) Sample 4 (Zinc acetate to PVA ratio 2 doped with $0.23 \mathrm{~g}$ boric acid).

Evidently, the absorption peaks at $1400-1450 \mathrm{~cm}^{-1}\left(\mathrm{CH}_{2}\right.$ bending $)$ and $850 \mathrm{~cm}^{-1}(\mathrm{CH} 2$ rocking) characteristic to PVA are obvious in all of the spectra [18]. Also, there may be some ester formation in the product due to the presence of $C=O$ peak at $1740 \mathrm{~cm}^{-}$ 1. A peak observed at $610 \mathrm{~cm}^{-1}$ indicates the $\mathrm{Zn}-\mathrm{O}$ bending. Unlike the first 3 peaks, at 4 the absorption peak observed at around $1430 \mathrm{~cm}^{-1}$ can be ascribed to the B-O stretching vibration. Also, the band at around $680 \mathrm{~cm}^{-1}$ which splits off when boric acid is added could be assigned as $\mathrm{B}-\mathrm{O}$ bending at this wavenumber [15-18]. 


\section{Conclusions}

In this study, PVA containing zinc acetate and boric acid bulk hybrid composite polymers have been successfully electrospun. Electrospinning of first sample precursor occurs easily on aluminum foil and can be taken out easily from the foil. The spinning processes became more cumbersome for solution 2 and especially solution 3 when boric acid was added which formed a very thin coating on foil. Therefore the spinning time was increased and the spinning rate decreased in order to increase the quality of the final product. The fiber produced from solutions 4 and 5 , which included boric acid, formed spider web like structure between syringe and collector instead of depositing on the aluminum foil.

Although voltages like $20 \mathrm{kV}$ were achieved with the first three solutions without any problem, the system became highly unstable causing big fluctuations in the voltage and forming beads even for drops of solutions 4 and 5 when voltages above $13 \mathrm{kV}$ were applied.

FTIR spectra showed characteristic peaks of PVA/ zinc acetate and PVA/ Zinc acetate/ Boric Acid. According to the SEM pictures, crosslinking and fiber density increased on increasing the amount of $\mathrm{Zn}$ acetate and boric acid.

\section{Experimental}

PVA, 98-99\% hydrolyzed granule $\left(M_{w}\right.$ 70000) was purchased from Merck. The solutions were prepared by dissolving PVA powder in a solution of zinc acetate $\left.\left(\mathrm{CH}_{3} \mathrm{COO}\right)_{2} .2 \mathrm{H}_{2} \mathrm{O}\right)$. The mixture was stirred using magnetic stirrer for $3 \mathrm{~h}$ at room temperature to form a homogeneous solution. The stirring was continued for another $5 \mathrm{~h}$ at $50{ }^{\circ} \mathrm{C}$ for the reaction to occur between PVA and $\mathrm{Zn}\left(\mathrm{CH}_{3} \mathrm{COO}\right)_{2} .2 \mathrm{H}_{2} \mathrm{O}$ solution. Three solutions were prepared with zinc acetate to PVA ratio of 1,2 and 3 respectively which were numbered as solution I, II and III. Two other solutions were prepared by adding $0.23 \mathrm{~g}$ and $0.70 \mathrm{~g}$ boric acid (BA) (Merck, $M_{\mathrm{w}} 61.83 \mathrm{~g} / \mathrm{mole}$ ) to solution II.

The composite solution for spinning was loaded into a $10 \mathrm{~mL}$ hypodermic stainless steel syringe with a needle $(0.8 \mathrm{~mm}$ in diameter and $38 \mathrm{~mm}$ length) connected to a digitally controlled pump(New Era) which provides a constant feeding rate [10]. The positive electrode of a high-voltage power supply (SP-30P) was placed on to the top of the needle. The negative electrode was connected to a metallic stationary collector wrapped with aluminum foil and served as a counter electrode and spun under 10-20 kV. The working distance (WD) between the tip of the syringe needle and the collector was $9-13 \mathrm{~cm}$. Composite fibers were collected on a aluminum foil , dried at $60{ }^{\circ} \mathrm{C}$ under vacuum for $10 \mathrm{~h}$.

The composite fibers were subjected to various characterization methods such as FT-IR, TG-DTA, DSC and SEM. The conductivities were measured by the use of four point probe method (ENTEK Company).

\section{Acknowledgements}

The authors acknowledge the Scientific and Technological Research Council of Turkey (TUBITAK) Project contract number 106T630 and 106T667. The authors also thank Prof. Dr. Orhan ATAKOL for TGA and DSC analyses and Dr. Erman BENGÜ for SEM images. 


\section{References}

[1[ Li, Z. ; Huang, H.; Wang, C. Macromol. Rapid Commun. 2006, 27, 152.

[2] Han, W.Q.; Fan, S.S.; Li, Q.Q.; Hu, Y.D. Science 1997, 277, 1287.

[3] Wu, H.; Pan, W. J. Am. Ceram. Soc. 2006, 89[2] 699.

[4] Kosobudsky, I..; Ushakov, N.; Yurkov, G.; Zapsis, K.; Kochubei, V.; Baranov D.; Dotsenko, I.; Zhuravleva, M.; Ponomareva, K.; Gubin, S. Inorganic Materials 2005, 41, 1172.

[5] Qin, X.; Wang, S. Journal of Applied Polymer Science 2006, 102, 1285.

[6] Liu, J.J.; Yu, M.H.; Zhou, W.L. Apply. Phys. Lett. 2005, 87, 172505.

[7] Wang, R.C.; Liu, C.P.; Huang, J. L.; Chen, S.J. Apply. Phys. Lett. 2006, 88, 023111.

[8] Hsu, C.L.; Chang, S.J.; Hung, H.C.; Lin, Y.R.; Chen, I.C. J.Electrochem.Soc. 2005, 152, 378.

[9] Yamamoto, Y.; Saitoa, K.; Takahashia, K. and Konagaib, M. Solar Energy Materials \& Solar Cells 2001, 65, 125.

[10] Siddheswaran, R. Cryst. Res. Technol. 2006, 41, 446.

[11] Lokhande, B. J.; Patil, P. S.; Uplane, M. D. Physica. B, Proceedings of the Yamada Conference LIV, The 9th International Conference on Shallow-Level Centers in Semiconductors, SLCS-9, held in Awaji Island, Hyogo, Japan, 24-27 September 2000.

[12] Abdalla, M.O.; Ludwick, A.; Mitchell, T. Polymer 2003, 44, 7353.

[13] Gao, J.; Yanfang, L.; Wang, F. Eur Polym J. 2001, 37, 2007.

[14] Hamad, S.; Haque, M.M.; Ashraf, S.M.; Ahmad, S. Eur Polym J. 2004, 40, 2097.

[15] Yang, X.; Shao, C.; Guan, H.; Li, X.; Gong, J. Inorganic Chemistry Communications 2004, 7, 176.

[16] Lin, D.; Pan, W.; Wu, H. J. Am. Ceram. Soc. 2007, 90, 71.

[17] Viswanathamurthil, P.; Bhattarai, N.; Kim, H. Y.; Lee, D.R. Nanotechnology 2004, 15, 320.

[18] Junkasem, J.; Rujiravanit, R.; Supaphol, P. Nanotechnology 2006, 17, 4519. 